\title{
Effortful Control and Academic Achievement in Rural China
}

\author{
Li Zhang ${ }^{a}$ and Nirmala Rao ${ }^{b}$

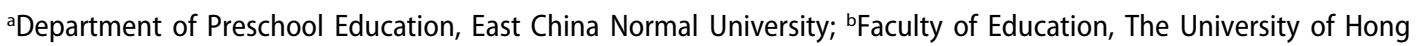 \\ Kong
}

\begin{abstract}
Research Findings: This study investigated the relationships between effortful control and early literacy and mathematics achievement. A total of 181 children (85 girls and 96 boys) from rural China were assessed when they were in Grades 1 and 2. Path analyses controlling for maternal education indicated that effortful control at the beginning of Grade 1 predicted incremental achievement in literacy and mathematics at the end of Grade 1 and mathematics achievement at the end of Grade 2. Growth in effortful control during Grade 1 also contributed significantly to the prediction of both literacy and mathematics achievement at the end of Grade 2 . Although girls performed significantly better than boys in literacy achievement, gender did not moderate the relationships between effortful control and literacy and mathematics achievement. Practice or Policy: Children's effortful control appears to be an important predictor of early literacy and mathematics achievement. Findings suggest that children's effortful control should be fostered during the preschool and early years of formal schooling, and this can be done in both home and school contexts.
\end{abstract}

In recent years, increased attention has been accorded to understanding components of self-regulation as they relate to children's preparedness for school (McClelland, Acock, \& Morrison, 2006). Self-regulation is an umbrella term for an array of skills that an individual is required to possess in order to participate in goal-directed activities. Effortful control (EC), defined as "the ability to inhibit a dominant response, and/or to activate a sub-dominant response, to plan, and to detect errors," is an important component of self-regulation (Rothbart \& Bates, 2006). Numerous studies have found that EC contributes to child outcomes and academic achievement both concurrently and longitudinally (Chen et al., 2015; Gestsdottir et al., 2014; Stipek, Newton, \& Chudgar, 2010; Valiente et al., 2011) and influences achievement in adulthood (McClelland, Acock, Piccinin, Rhea, \& Stallings, 2013).

Poverty and gender affect the development of EC. Children living in poverty have poorer EC skills and relatively lower levels of academic achievement than their more advantaged peers (Chung, Liu, Mcbride, Wong, \& Lo, 2016; Welsh, Nix, Blair, Bierman, \& Nelson, 2010). There are positive correlations among levels of poverty, maternal education, young children's EC, and early achievement. Indeed, maternal education predicts children's EC, including attention and behavioral control, and attainment in reading and mathematics (Howse, Lange, Farran, \& Boyles, 2003; Sektnan, McClelland, Acock, \& Morrison, 2010). In terms of gender difference, girls tend to show better EC, more persistence, and higher academic achievement in school than boys (Li-Grining, Votruba-Drzal, Maldonado-Carreno, \& Haas, 2010; Ready, LoGerfo, Burkam, \& Lee, 2005). Furthermore, research suggests that gender moderates the relationship between children's EC and early reading and that EC is more important in predicting reading achievement in boys than in girls (Son, Lee, \& Sung, 2013).

CONTACT Li Zhang Izhang@pie.ecnu.edu.cn Department of Preschool Education, Faculty of Education, East China Normal University, 3663 North Zhongshan Road, Shanghai 200062, China.

(c) 2016 Taylor \& Francis 
The majority of the aforementioned findings were drawn from studies conducted in Western contexts. In recent years, research on the early developmental outcomes of children from economically disadvantaged families in developing countries has received increasing attention (Rao, Sun, Wong, et al., 2014). However, there is dearth of research linking EC in the early years and academic achievement among children experiencing economic adversity in developing countries.

As a developing country, China has a large population residing in rural areas, and because of limited resources and economic opportunities, many parents from these areas seek jobs in urban areas and cities, leaving their children-especially preschoolers-at home. Statistics suggest that about 60 million such left-behind children reside in rural areas (Ma, 2015) and that they receive little educational support from their parents. This highlights the need for early childhood education for the development of children in rural areas. Nevertheless, few empirical studies have been conducted to examine developmental outcomes and achievement among these children.

Chinese society reflects a strong emphasis on behavioral inhibition and self-restraint, with inhibited children usually regarded positively as mature and well behaved (X. Chen, Wang, \& Cao, 2011; Rao, Sun, \& Zhang, 2014). Chinese children have been shown to display higher levels of behavioral inhibition or EC than their peers in other cultures (X. Chen et al., 2011; Chung et al., 2016; Wanless et al., 2013). This may give them an advantage in academic achievement; however, few studies have critically examined the association between EC and academic achievement among Chinese children, especially those from poor and rural areas, who are at risk for poor school achievement. Therefore, this study explored the relationship between EC and academic achievement over time among children in Grades 1 and 2 in rural China.

\section{EC and Academic Achievement}

EC predominantly captures attention shifting, persistence, voluntary behavioral inhibition, error detection, and action planning (Rothbart \& Bates, 2006; Valiente, Lemery-Chalfant, Swanson, \& Reiser, 2008; Zhou, Chen, \& Main, 2012). These skills are typically assessed through ratings by parents and teachers (Zhou et al., 2012; Zhou, Main, \& Wang, 2010) and children's performance on behavioral tasks (Valiente et al., 2011). Such tasks typically require children to suppress a dominant response in favor of a less dominant one. The use of behavioral tasks avoids problems associated with adults' retrospective reports. The Head-Toes-Knees-Shoulders (HTKS) task, a variant of the Simon Says game, is one such behavioral measure that can be used to assess EC (Cameron, McClelland, Matthews, \& Morrison, 2009). The HTKS has been widely applied in different cultural contexts, such as the United States, South Korea, China, and several European countries (Cadima, Gamelas, McClelland, \& Peixoto, 2015; Gestsdottir et al., 2014; Størksen, Ellingsen, Wanless, \& McClelland, 2015; Wanless et al., 2013). The present study also used the HTKS task as an indicator of EC.

Self-regulation skills and academic achievement are theorized to be reciprocally related (Blair, Calkins, \& Kopp, 2010). It might be inferred that EC-as an important component of self-regulation-might also be associated with school achievement and vice versa. However, most studies have examined the contribution of EC to school achievement instead of the reciprocal relationship between the two variables (Swanson, Valiente, Lemery-Chalfant, Bradley, \& Eggum-Wilkens, 2014). Findings consistently show that EC in preschool, assessed through both adult report and direct measures, is associated with academic achievement in children across cultures (including the United States, European countries, China, and other Asian countries), family wealth (from low-income families to upper middle-class families), and child age (including children in their preschool years and early primary school years; Blair \& Razza, 2007; Cadima et al., 2015; Chen et al., 2015; Gestsdottir et al., 2014; Schmitt, McClelland, Tominey, \& Acock, 2015; Størksen et al., 2015; Wanless et al., 2013; Zhou et al., 2010).

Few studies have examined the reciprocal relationship between EC and academic achievement. Several studies have found that EC predicts academic achievement but not vice versa. For example, Zhou et al. (2010) found that EC in first and second graders in China predicted their mathematics 
and Chinese language scores when they were in the fifth and sixth grades but that their earlier academic achievement did not predict later EC. Furthermore, some researchers have identified the factors that mediate the relationship between EC and academic achievement and have shown that EC is a predictor of academic competence but not vice versa. The mediators include the teacherchild relationship and classroom participation (Liew, Chen, \& Hughes, 2010; Valiente et al., 2008) and children's social functioning (Valiente et al., 2011), school liking (Valiente, Lemery-Chalfant, \& Castro, 2007), and beliefs about academic self-efficacy (Liew, McTigue, Barrois, \& Hughes, 2008). However, one study by Swanson and colleagues (2014) demonstrated that children's mathematics achievement in kindergarten predicted EC in Grade 1, but in Grade 2 their EC predicted mathematics achievement instead, which shows the cross-grade reciprocal association between the two child outcomes. The inconsistency of these findings necessitates further research on the relationship between EC and academic performance.

\section{Child Rearing and Education in the Chinese Context}

Child rearing and education in different ethnic groups in China, including ethnic minorities such as the Miao group involved in the present study, are profoundly affected by Confucian values $(\mathrm{Wu}$, 2016). This is evident in both home and school contexts. Parents emphasize propriety and socialize children to show respect for elders and authority, to be obedient and modest, and to regulate behavior and emotion, especially in public (Rao, Sun, \& Zhang, 2014). Parents' socialization goals for their children and parent-child interaction in the early years may therefore influence the development of EC in the early years.

Similarly, in Chinese classrooms, there is an emphasis on classroom discipline, teacher authority, mastery of knowledge, drill and practice, and the exertion of effort (Rao, Ng, \& Pearson, 2010; Tobin, Hsueh, \& Karasawa, 2009). School programs are highly structured, and young children are trained to control behavior and emotions, obey teachers' instructions, and comply with classroom discipline (Rao et al., 2010; Rao, Sun, \& Zhang, 2014). Chinese teachers typically exert more control than teachers in other parts of the world when children become distracted or when the teacher's voice is not heard clearly in the classroom (Liu \& Elicker, 2005). It is assumed that these classroom experiences contribute to Chinese children showing higher levels of self-control than Western children. For instance, Chinese children are found to exhibit higher levels of inhibition and attentional control in Grade 1 classrooms in comparison with their counterparts in the United States (Lan et al., 2009).

Chinese culture places a strong emphasis on academic achievement (Luo, Tamis-LeMonda, \& Song, 2013; Rao, Sun, \& Zhang, 2014). Chinese parents have high expectations for children's achievement, even for young children. In order to cater to parental demands and generate more income, even preschool programs in China stress didactic teaching (Pang \& Richey, 2007). Repeated practice and memorization are stressed, and children are encouraged to exert considerable effort to acquire knowledge (Rao, Sun, \& Zhang, 2014).

\section{The Present Study}

China has a high Gini coefficient (level of inequality of national income distribution), which is due in large part to marked differences in urban-rural economic development. As noted earlier, many parents seek jobs in cities because of limited economic opportunities in rural areas and leave their young children behind in rural areas. These so called left-behind children often lack cognitive stimulation and have fewer opportunities for home-based learning (L. J. Chen, Yang, \& Ren, 2015; Zhang, 2008). This reduced stimulation and exposure may have a negative impact on children's early development and achievement. There is, therefore, a need to examine school readiness skills and academic achievement among these children in order to facilitate their formal schooling. A considerable amount of research indicates that EC is associated with academic achievement both 
concurrently and longitudinally, but it is not yet clear whether academic achievement also positively predicts EC. To our knowledge, no study has linked EC and academic achievement in children from rural China. Against this background, this study explored EC and academic achievement in a group of Chinese rural children.

Welsh and colleagues (2010) examined the association between growth in cognitive processes (working memory and attention control) and growth in academic achievement (literacy and mathematics achievement) across the prekindergarten and kindergarten years among children from lowincome families. Although the study did not examine children's EC, the research helped to identify whether the relationship between cognitive processes and academic performance is reciprocal and whether children's preschool cognitive and academic skills predict literacy and mathematics competence in kindergarten. The research design, especially the determination of longitudinal waves and the methods of analyses, informed the methodology of the current study. Unlike in the United States, where the kindergarten year is compulsory, Grade 1 is the first year of formal, compulsory education for children in China and is regarded as the key year for children to adjust to school. For this reason, the present study focused on children at school entry and followed them for 2 years (at the beginning and at the end of Grade 1 and at the end of Grade 2). This allowed for an examination of children's EC and academic achievement during the transition from early childhood education to early primary school education.

First, the reciprocal relationship of EC to literacy and mathematics achievement across Grade 1 was examined. In line with the existing literature, we assumed that EC would predict literacy or mathematics achievement in the first year of primary school and that earlier academic performance would also contribute to later EC.

Second, the predictive effects of the development of EC and academic achievement during Grade 1 on literacy and mathematics achievement at the end of Grade 2 were explored. We hypothesized that growth in both EC and academic achievement during Grade 1 would contribute to Grade 2 literacy and mathematics achievement.

Third, the moderating effect of gender on the relationship between EC and academic achievement was investigated. Maternal education level was included as a covariate in the analyses, as previous studies have found that it is associated with children's EC and achievement in language, mathematics, and reading (Howse et al., 2003; Sektnan et al., 2010). Based on existing findings (Son et al., 2013), we assumed that gender would moderate the association between the two child outcomes after we controlled for maternal education.

\section{Method}

The current research is part of a three-wave longitudinal study. Demographic information and data on academic achievement in the first two waves were presented in Rao, Sun, Zhou, and Zhang (2012). This article presents data on EC that have not been previously reported. In addition, the current article reports on additional data collected during Wave 3.

\section{Participants}

A total of 207 children, 95 girls and 112 boys, were recruited from 10 primary schools in ABC County, in Guizhou Province of China, soon after they were enrolled in Grade 1 (G1 fall). The selection of children was based on their former preschool experience (attending kindergarten or separate preprimary class, sitting in Grade 1 or having no preschool experience). Some Grade 1 classes in poor and rural areas enroll children younger than 7 years-the age at which children in rural areas start formal primary school. These children are considered sitting-in children. This sitting-in experience is provided for several reasons. First, it allows children, particularly those who do not speak Mandarin Chinese as a first language, to have earlier exposure to Mandarin Chinese and the formal Grade 1 curriculum in the hope that they will be more engaged with the 
school curriculum when they formally enroll in primary school. Second, it is allowed when there are no early childhood services in the county that are affordable for poor families (Rao et al., 2012). All of the schools and preschool programs in China use Mandarin Chinese as the language of instruction. Of the 10 schools in our sample, one enrolled children from the only kindergarten, and all 62 children were recruited. Four schools enrolled children from separate preprimary classes and five enrolled children from sitting-in classes. In each school, eight to 20 children, with nearly equal numbers of boys and girls, were randomly selected based on the number of children enrolled in Grade 1. Few children had no preschool experience, and we recruited as many of them as possible $(n=20)$ to include children with a range of preschool experiences. The recruited children also had a wide age range. Some children younger than 7 years are evaluated by teachers as competent learners after 2 to 3 years of sitting-in experience. These children are formally enrolled in Grade 1 before they are 7 years. However, some children's first formal educational experience only occurs after they enroll in Grade 1, and they are older than 7 years when this occurs. The latter have had no preschool experience. Parents/guardians of all children provided family demographic information.

Data from two children were excluded from the analyses, as these children were found to be significantly older than the other children. Another 10 dropped out at different waves, three at the second wave (G1 summer) and seven at the third wave (G2 summer). Five children were excluded because they were repeating Grade 1. In addition, another nine missed most of the assessments (academic achievement tests and EC task) in at least two waves of the study. Therefore, the final sample consisted of 181 children, 85 girls and 96 boys, with a mean age of 86.87 months and an age range of 69 to 108 months $(S D=4.96)$.

The sample consisted of children from diverse ethnic groups and from low-income families at the research site. About $51.4 \%$ of the children were Han, $32.6 \%$ were from the Buyi ethnic minority group, and $16 \%$ were from the Miao and other ethnic minority groups. The different ethnic minority groups acknowledge and accept Chinese culture and values. For instance, the Buyi ethnic group has assimilated into the prevalent Han Chinese culture well, and the Miao group follows Confucian values ( $\mathrm{Wu}, 2016)$. A total of 104 children had been left behind by one of their parents or both and were being taken care of by their grandparents or by other relatives at home. The annual per capita net income of these local families averaged \$305 USD, which is much below the median for rural families (\$686 USD; National Bureau of Statistics of the People's Republic of China, 2009; The Government of ABC County, 2009). Mothers of these children had an average of 3.81 years of formal education, and about $34.8 \%$ of them had not received any formal education.

\section{Procedure}

Before each wave of the study, principals, teachers, and parents/guardians were informed of the objectives of the study, and consent for children's participation was obtained. Children's EC was assessed at the beginning and at the end of Grade 1 (G1 fall and G1 summer) in individual sessions. Tests were administered by trained research assistants in quiet and unused rooms in children's schools. Children also completed two group-based tests (mathematics and literacy attainment tests) in each wave (G1 fall, G1 summer, and G2 summer). Parents or guardians were interviewed individually to obtain information about the families. All participants were given small gifts after each wave of the study, and the schools were sent some sporting goods.

All tests were administered in Mandarin Chinese for the following reasons. First, as noted earlier, Chinese is the official language of instruction in all preschools and schools in China, and children who attended preschool had been exposed to Mandarin Chinese prior to school entry. Second, children from the Buyi ethnic minority group used the same local dialect as the Han Chinese group. Some children from the Miao ethnic group did speak the Miao dialect. However, as there is no writing system associated with the 
Miao dialect, fewer and fewer people are able to speak the dialect. Third, teachers were enlisted to help explain test requirements to several children who did not have a good command of Mandarin Chinese. The former were fluent in the dialects spoken by these children.

\section{Measures}

\section{EC Task}

The revised HTKS task was used to measure children's EC. In the original task, children are given two rules-touching one's head is the opposite of touching one's toes, and touching one's shoulders is the opposite of touching one's knees-and are then asked to respond to 20 items in two phases (10 items for each phase). Phase 1 includes only one rule; Phase 2 contains two rules, and children are required to respond using either rule. As Chinese children show better regulation skills than their Western and other Asian peers (X. Chen et al., 2011), they may achieve very high scores in this task when entering primary schools. Therefore, some modifications were made to increase the difficulty level. First, only the Phase 2 items of the original task were used, and as children made very few self-corrections, a correct response was scored 1 instead of 2 . Second, an additional 10 items that required children to respond based on both rules were added. For instance, if a child was required to touch his or her head and knees, he or she should have touched his or her toes and shoulders. A score of 2 was given for a correct response, 1 was given for responses that were in reverse order, and 0 was given for no response or for an incorrect response. The entire task took about 20 to $30 \mathrm{~min}$ for each child. A pilot test conducted with 10 children (five girls) showed that the modified task was appropriate and that children could understand the instructions. Cronbach's alphas for the whole task in G1 fall and G1 summer were .91 and .87, respectively. Interrater reliability was established based on an assessment of 20 children in G1 fall and indicated strong interrater agreement $(\kappa=.85, p<.05)$.

\section{Academic Achievement Tests}

Achievement tests were developed by the researchers and two local senior teachers on the basis of stateissued guidelines for curriculum in primary schools (Ministry of Education, 2002a, 2002b), Grade 1 and Grade 2 textbooks (Institute of Curriculum and Teaching Materials, \& Research and Development Center for Language Curriculum and Teaching Materials for Primary Schools, 2007, 2008a, 2008b, 2008c), as well as examination papers developed in the previous year by the local education department. Two sets of test papers (including literacy and mathematics tests) were prepared, with one set for children in Grade 1 and the other for Grade 2 (see the Appendix). The Grade 1 set was used in the study by Rao et al. (2012). All tests were completed in approximately $45 \mathrm{~min}$.

Tests for Grade 1 were administered to children at G1 fall (Wave 1) and G1 summer (Wave 2). The literacy test (as $=.96$ and .97 for Wave 1 and Wave 2, respectively) was composed of four subtests: pronunciation, writing characters, combining words and sentences, and a short passage for comprehension. The mathematics test ( $\alpha=.94$ and .93 for Wave 1 and Wave 2, respectively) consisted of three subtests: counting, comparison, and calculation (including applied problem solving). The tests for Grade 2 were administered when children were at the end of Grade 2 (Wave 3). Similar to that in the Grade 1 set, the literacy test $(\alpha=.95)$ was composed of items such as writing characters, combining words, making up or completing sentences, reading comprehension, and a short passage writing. The mathematics test $(\alpha=.91)$ involved items such as knowledge of measuring units and numbers, comparison, and calculation (including applied problem solving).

A total of 20 Grade 1 and Grade 2 teachers from eight of the participant children's classes from eight participant schools were invited to comment on the tests and to estimate the average score for each test. The teachers all acknowledged that the tests did assess academic content for the corresponding grade of children, and the average scores they estimated for the literacy and mathematics tests for Grades 1 and 2 were 63, 60, 60, and 53, respectively. 


\section{Results}

There were relatively few missing data for the three outcome variables across the three waves of the study. The sample size for each variable is shown in Table 1, with the highest rate of missingness occurring for EC (11.05\%) at the beginning of Grade 1. There was no significant difference in EC at the end of Grade 1 between children who completed this measure at the beginning of Grade 1 and those who did not, $t(174)=0.37, p>.05$. Less than $2 \%$ of the data were missing for all measures at the end of Grade 2. Missing values for each variable were accounted for using the expectationmaximization algorithm (SPSS Inc., 2008). We detected outliers by inspecting frequency distributions of $z$ scores for all variables. No case was found to have extreme scores on two or more variables, but there were some extreme scores for one variable. This means that there were no multivariate outliers but that univariate outliers existed. Following Kline (2011), we used $|z|>3.00$ as the cutoff point for the univariate outlier. Therefore, three outliers were identified for children's G1 fall literacy achievement, G1 summer mathematics achievement, and G1 summer EC scores, respectively. The outliers were replaced with the values of the next most extreme scores that were within $3 S D$ of the mean (Kline, 2011).

As indicated in Table 1, children had low scores in both literacy and mathematics achievement through the three waves. All average scores were below scores estimated by teachers. For EC at Wave 1 and Wave 2, mean scores were 19.14 and 21.27 , respectively, out of 30 points $(2.76 \%$ and $6.08 \%$ at ceiling separately).

To examine the relationships between children's EC and literacy achievement and mathematics achievement across the first 2 years in school, we computed zero-order correlations. As presented in Table 2, most correlations between different variables were statistically significant at a probability level of .001. Children's EC and literacy achievement or mathematics achievement, both concurrently and across the 2 years, were moderately to strongly correlated (Campbell \& Swinscow, 2009). The correlation coefficients between EC and literacy achievement ranged from .20 $(p<.01)$ to .45 $(p<.001)$, and those between EC and mathematics achievement ranged from .24 $(p<.001)$ to .52 $(p<.001)$. Children with higher EC skills both at G1 fall and G1 summer tended to achieve higher scores in literacy and mathematics achievement across Grades 1 and 2.

It should also be noted that maternal education level was significantly correlated with both EC and academic achievement $(r s=.16-.37)$ in all waves. Children whose mothers had higher levels of education tended to perform better in EC and academic achievement through all waves. Gender was also significantly correlated with literacy achievement measured at the end of Grade $1(r=.24$, $p<.01)$ and Grade $2(r=.21, p<.01)$, with girls showing relatively higher levels of literacy skills than boys. Children's left-behind status did not correlate with any child outcomes in EC or academic achievement throughout the three waves $(p s>.05)$ and thus was not included in further analyses.

Table 1. Descriptive statistics for predictor and outcome variables.

\begin{tabular}{|c|c|c|c|c|c|c|}
\hline Variable & $\%$ & M & SD & Range & Total Score & $\mathrm{N}$ \\
\hline Child's age (in months) & & 86.87 & 4.96 & $69-108$ & & 181 \\
\hline Percent left behind & 58 & & & & & 181 \\
\hline Ethnicity (percent Buyi) & 33 & & & & & 181 \\
\hline Ethnicity (percent Miao or other) & 16 & & & & & 181 \\
\hline Percent female & 47 & & & & & 181 \\
\hline Mother's education (years in school) & & 3.81 & 3.67 & $0-15$ & & 181 \\
\hline Literacy (G1 fall) & & 25.75 & 17.65 & $1-78$ & 100 & 175 \\
\hline Literacy ( $\mathrm{G} 1$ summer) & & 58.75 & 22.21 & $7-94$ & 100 & 173 \\
\hline Literacy (G2 summer) & & 41.95 & 25.55 & $0-93.50$ & 100 & 180 \\
\hline Mathematics (G1 fall) & & 24.09 & 11.77 & $1-57$ & 100 & 175 \\
\hline Mathematics (G1 summer) & & 43.93 & 12.56 & $11-65$ & 100 & 179 \\
\hline Mathematics (G2 summer) & & 40.03 & 21.64 & $0-94$ & 100 & 179 \\
\hline Effortful control (G1 fall) & & 19.14 & 6.91 & $1-30$ & 30 & 161 \\
\hline Effortful control (G1summer) & & 21.27 & 6.68 & $2-30$ & 30 & 176 \\
\hline
\end{tabular}

Note. G1 = Grade 1; G2 = Grade 2. 
Table 2. Zero-order correlations between all variables modeled in the path analysis across three waves.

\begin{tabular}{|c|c|c|c|c|c|c|c|c|c|c|c|}
\hline Measure & 1 & 2 & 3 & 4 & 5 & 6 & 7 & 8 & 9 & 10 & 11 \\
\hline \multicolumn{12}{|l|}{ Time 1} \\
\hline 1. G1 fall effortful control & - & & & & & & & & & & \\
\hline 2. G1 fall literacy & $.30 * * *$ & - & & & & & & & & & \\
\hline 3. G1 fall mathematics & $.39 * * *$ & $.59 * * *$ & - & & & & & & & & \\
\hline \multicolumn{12}{|l|}{ Time 2} \\
\hline 4. G1 summer effortful control & $.61^{* * *}$ & $.20^{* *}$ & $.24^{* *}$ & - & & & & & & & \\
\hline 5. G1 summer literacy & $.45^{* * *}$ & $.44^{* * *}$ & $.37^{* * *}$ & $.39 * * *$ & - & & & & & & \\
\hline 6. G1 summer mathematics & $.47^{* * *}$ & $.52^{* * *}$ & $.57^{* * *}$ & $.45^{* * *}$ & $.65^{* * *}$ & - & & & & & \\
\hline \multicolumn{12}{|l|}{ Time 3} \\
\hline 7. G2 summer literacy & $.40^{* * *}$ & $.39 * * *$ & $.31^{* * *}$ & $.41^{* * *}$ & $.70^{* * *}$ & $.52^{* * *}$ & - & & & & \\
\hline 8. G2 summer mathematics & $.52^{* * *}$ & $.47^{* * *}$ & $.37^{* * *}$ & $.49^{* * *}$ & $.72^{* * *}$ & $.62^{* * *}$ & $.81^{* * *}$ & - & & & \\
\hline \multicolumn{12}{|l|}{ Covariates } \\
\hline 9. Maternal education level & $.29 * * *$ & $.16^{*}$ & $.16^{*}$ & $.27^{* * *}$ & $.20^{* *}$ & $.28^{* * *}$ & $.29 * * *$ & $.37^{* * *}$ & - & & \\
\hline 10. Gender $(0=$ boy, $1=$ girl $)$ & -.06 & .11 & .07 & -.09 & $.24^{* *}$ & .11 & $.21^{* *}$ & .01 & -.04 & - & \\
\hline 11. Left behind ( $0=$ no, $1=$ yes) & -.07 & -.00 & -.09 & -.06 & .06 & -.03 & .14 & -.01 & -.02 & $.21^{* *}$ & - \\
\hline
\end{tabular}

Note. G1 = Grade 1; G2 = Grade 2.

${ }^{*} p<.05 .{ }^{* *} p<.01 .{ }^{* * *} p<.001$.

Next, two path analysis models were used to predict children's literacy and mathematics achievement at the end of Grade 2. The models tested whether EC at the beginning of Grade 1 predicted growth in literacy or mathematics achievement and whether initial literacy or mathematics achievement accounted for growth in EC during Grade 1. The models also examined whether growth in EC and literacy or mathematics achievement in Grade 1 contributed to academic achievement at the end of Grade 2. Figures 1 and 2 indicate the results of the path analyses for literacy and mathematics achievement at the end of Grade 2. All scores for different measures were standardized, and the estimates provided are standard coefficients.

\section{Longitudinal Model Predicting Grade 2 Literacy Achievement}

The saturated model examining the relationship between EC and literacy achievement throughout the three waves, controlling for maternal education level, was established first. Then the nonsignificant paths were removed, and the path model was established again. All of the paths for the model examining the association between EC and literacy achievement are shown in Figure 1. Results showed that the association between EC and literacy achievement fit the data well, $\chi^{2}(5)=5.45, p=.36$, Bentler comparative fit index $(\mathrm{CFI})=1.00$, root mean square error of approximation (RMSEA) $=.02$, standardized root-mean-square residual $(\mathrm{SRMR})=.03$ (see Figure 1$)$. Children's EC at G1 fall was significantly correlated with

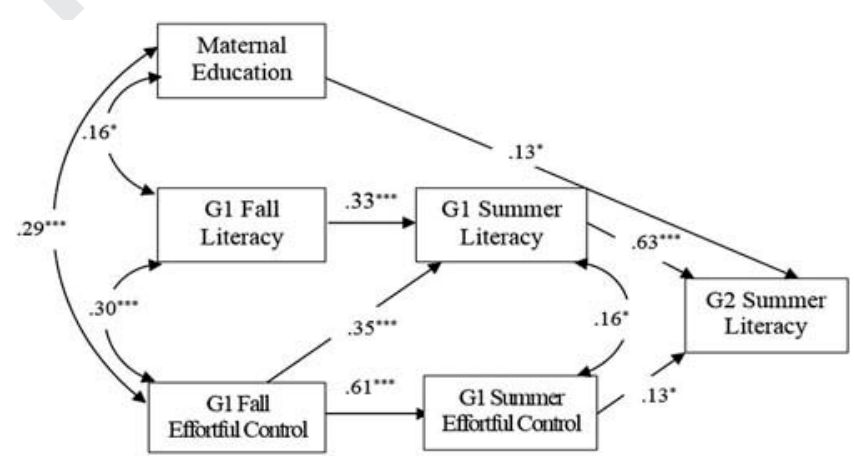

Figure 1. Path model for $\mathrm{G} 2$ literacy achievement, $\mathrm{X}^{2}(5)=5.45, p=.36$, root mean square error of approximation $=.02$, comparative fit index $=1.00 . \mathrm{G} 1=$ Grade $1 ; \mathrm{G} 2=$ Grade $2 .{ }^{*} p<.05 .{ }^{* * *} p<.001$. 


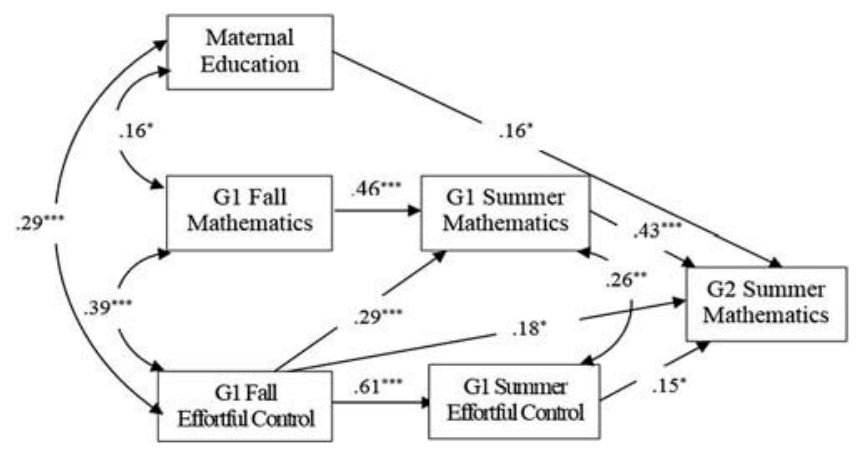

Figure 2. Path model for $\mathrm{G} 2$ mathematics achievement, $\mathrm{X}^{2}(4)=6.30, p=.18$, root mean square error of approximation $=.06$, comparative fit index $=.99 . \mathrm{G} 1=$ Grade $1 ; \mathrm{G} 2=$ Grade $2 .{ }^{*} p<.05 .{ }^{* *} p<.01$. ${ }^{* * *} p<.001$.

concurrent literacy achievement and also predicted growth in literacy skills $(\beta=.35)$ across Grade 1, even after we controlled for initial level of literacy achievement. However, literacy achievement at G1 fall did not predict EC at G1 summer. This part of the cross-lagged path model evidences that EC contributes to growth in literacy achievement during the first year in school but not vice versa. Children who had higher levels of EC attained higher levels of literacy achievement at the end of Grade 1, but higher initial literacy scores did not entail higher levels of EC at the end of Grade 1.

The model also illustrates predictors of literacy achievement at the end of Grade 2. Growth in literacy achievement in Grade 1 accounted for high variance in literacy achievement at the end of Grade $2(\beta=.63)$. Moreover, growth in EC had an extra, unique influence on literacy achievement at this wave $(\beta=.13)$ when we controlled for growth in literacy achievement in the same period. Therefore, partially consistent with our hypothesis, initial EC contributed to growth in literacy achievement during Grade 1, and growth in both EC and literacy achievement in Grade 1 significantly predicted literacy achievement at the end of Grade 2. However, literacy achievement did not predict EC during Grade 1.

\section{Longitudinal Model Predicting Grade 2 Mathematics Achievement}

A parallel path model was established predicting mathematics achievement at the end of Grade 2. 350 The model appeared to fit the data well, $\chi^{2}(4)=6.30, p=.18$, Bentler CFI $=.99$, RMSEA $=.06$, standardized SRMR $=.04$ (see Figure 2). G1 fall EC was significantly associated with concurrent mathematics skills and predicted growth in mathematics achievement during Grade $1(\beta=.29)$ when initial levels of mathematics skills were controlled for. Similar to the model for literacy achievement, children's EC made a unique contribution to mathematics achievement during Grade 1 but not vice versa. Children who achieved higher levels of EC at the beginning of Grade 1 tended to gain higher scores in mathematics achievement at the end of Grade 1, but initial higher mathematics scores did not lead to higher EC at the end of Grade 1.

The model also presents predictors of mathematics achievement at the end of Grade 2. Both growth in mathematics achievement $(\beta=.43)$ and growth in EC $(\beta=.15)$ in Grade 1360 significantly predicted mathematics achievement at the end of Grade 2. In addition, the initial level of EC at the beginning of Grade 1 was also a significant predictor $(\beta=.18)$ of mathematics achievement. The results partially support the initial hypothesis that initial EC would contribute to growth in mathematics skills during Grade 1 and that growth in EC and mathematics achievement in Grade 1 would significantly predict mathematics achievement at 365 the end of Grade 2. However, mathematics achievement did not predict EC during Grade 1. 


\section{Moderating Effects of Child Gender}

To examine whether the paths between EC and academic achievement were the same for boys and girls, we carried out two multigroup analyses. A model with no equality constraints between the two groups was compared with a model with paths constrained to be equal for boys and girls. The comparison models were established separately for literacy achievement and mathematics achievement. Findings showed that gender did not lead to a significant chi-square change in the analyses for literacy achievement or mathematics achievement: literacy achievement, $\Delta \chi^{2}(5)=10.63$, $p=.06$; mathematics achievement, $\Delta \chi^{2}(7)=3.82, p=.58$ ). Thus, gender did not moderate the relationships between EC and academic achievement, which did not bolster our hypothesis.

\section{Discussion}

This study examined the association between EC and early academic achievement in rural China. A handful of studies have shown that EC predicts children's literacy and mathematics achievement in preschool and early primary school (Blair \& Razza, 2007; Chen et al., 2015; Liew et al., 2008; Swanson et al., 2014; Valiente et al., 2008, 2011; Zhou et al., 2010). However, little is known about the relationship between EC and early academic achievement among Chinese children. Against this background, this study extended existing research by examining the association between EC and academic achievement controlling for maternal education level and by exploring whether the relationship is moderated by child gender in rural China.

\section{The Relationship Between EC and Academic Achievement During Grade 1}

Consistent with findings from previous studies that have examined the relationship between EC and academic achievement among children in the early primary school years (Cadima et al., 2015; Gestsdottir et al., 2014; Liew et al., 2008; Schmitt et al., 2015; Stipek et al., 2010; Størksen et al., 2015; Swanson et al., 2014; Wanless et al., 2013; Zhou et al., 2010), we found that children's initial level of EC accounted uniquely for literacy and mathematics achievement after we controlled for concurrent growth in academic achievement during Grade 1. Children who had a higher level of EC at the beginning of Grade 1 were mostly likely to achieve higher literacy and mathematics scores at the end of Grade 1. Researchers argue that EC promotes children's academic achievement by bestowing several advantages. First, children with high levels of EC are able to focus on the task at hand, shift attention, and show persistence, which helps them to concentrate on teachers' instructions in class and persist in their assignments (Valiente et al., 2011). Second, EC helps children to initiate, sustain, and regulate motivation for learning and therefore promotes academic achievement (Valiente et al., 2011; Zhou et al., 2010). Third, children with a high level of EC are good at controlling negative behavior and emotions when faced with challenging situations in class (Blair, Ursache, Greenberg, \& Vernon-Feagans, 2015; Zhou et al., 2010). To get ready for school, children in this study, and those in China generally, need to learn to adapt to school routines (i.e., longer school hours, longer duration of each session, shifts between curriculum areas, and less recess time) and to display good learning-related behaviors (i.e., listening to teachers, paying attention in class, working independently, and inhibiting impulsive behaviors). These positive behaviors necessitate relatively high EC and contribute to success in school.

However, the reverse path, that is, the prediction of EC from initial literacy or mathematics achievement (G1 fall) at the end of Grade 1, was not found. In our study, children achieved very low literacy and mathematics scores at school entry, and their academic skills may not have been strong enough to stimulate EC and learning-related skills, including focused attention and task persistence. Few studies have examined how well academic achievement predicts EC, and there seem to be inconsistencies between findings. For example, Swanson et al. (2014) found that children's mathematics achievement assessed in the spring semester in kindergarten predicted EC in the fall semester 
in Grade 1, but the reverse path was not significant. Therefore, more research is required to examine whether earlier academic achievement predicts children's later EC.

\section{Predictors of Academic Achievement in Grade 2}

This study also examined how well EC and academic achievement in Grade 1 predicts literacy and mathematics achievement at the end of Grade 2 when maternal education level is controlled. Results showed that although growth in academic achievement accounted for huge variance in literacy and mathematics achievement in Grade 2, early EC skills still made a unique contribution. This finding is consistent with research documenting the significant role of EC in the prediction of later academic achievement in primary school children (McClelland et al., 2006; Stipek et al., 2010; Swanson et al., 2014; Zhou et al., 2010).

However, there was a difference in the paths from EC to literacy and to mathematics competencies in Grade 2. We found that initial EC level played a unique predictive role in mathematics achievement but not in literacy achievement. Results indicate that early EC makes more of a contribution to later mathematics achievement than to literacy achievement, which aligns with previous research (Blair \& Razza, 2007; Cameron et al., 2009; Chung et al., 2016). Researchers speculate that the problem-solving process in mathematics requires important elements of EC, including attention shifting and inhibitory control, whereas literacy requires less EC (Blair \& Razza, 2007; Blair et al., 2015; Cameron et al., 2009; Wanless et al., 2013). Features of the achievement tests in this study may also explain the results. The literacy achievement tests included many items in Mandarin Chinese Pinyin, Chinese characters, vocabulary, and words, which place a high demand on working memory and less on EC. The mathematics achievement tests examined children's command of numeracy, comparison, calculation, and problem solving, which requires children to shift between different rules frequently and inhibit resorting to incorrect solutions. Thus, the early EC skills required by the revised HTKS task may be especially important for later mathematics achievement.

\section{The Moderating Effect of Child Gender}

This study also explored whether child gender moderates the relationship between EC and academic achievement. Although there were significant differences between boys and girls in literacy achievement at the end of Grades 1 and 2, the relation between EC and literacy or mathematics competencies did not differ between the two groups. One possible reason for this may be that our study did not find gender differences in EC. Researchers have argued that Chinese society so strongly promotes EC that it permeates socialization practices across gender (X. Chen et al., 2011; Wanless et al., 2013), at least at the primary level. In rural China, children largely depend on classroom practices to develop EC skills and academic skills, and teachers do not differentiate between boys or girls in supporting the development of self-regulation skills and academic competencies.

Nevertheless, girls had better performance in literacy achievement, which aligns with results for students in Shanghai, Hong Kong, and many other countries in a PISA study (Organisation for Economic Co-operation and Development, 2014). Evidence has indicated that girls show more interest in language in places like the United States, Taiwan, and Japan (Evans, Schweingruber, \& Stevenson, 2002), which may give girls an advantage in literacy achievement. Regardless of gender differences in literacy achievement, the present study found that gender did not contribute to the relationship between EC and literacy achievement. This finding is consistent with a study conducted in the United States and Asian countries that indicated that gender does not contribute to the relationship between EC and school readiness skills, including early language and literacy skills (Wanless et al., 2013). In addition, this study found that boys and girls did not differ in mathematics achievement across the three waves. Therefore, it is reasonable that gender does not modify the association between EC and mathematics competencies. 


\section{Implications}

The findings of our study reveal the importance of EC at school entry, and as most children in our study participated in early childhood education, we suggest that preschool programs in rural China promote EC in their curriculum.

Research targeting low-income children has indicated that preschool programs containing training in EC skills improve children's self-regulation and academic achievement (Diamond, Barnett, Thomas, \& Munro, 2007; Diamond \& Lee, 2011). Activities such as computerized training and physical training, including traditional martial arts, aerobics, yoga, mindfulness, and some school curricula, have been shown to improve children's self-control (Diamond, 2012). Preschool programs and primary schools in rural China generally have difficulty accessing computers, so promoting physical activities may be a better choice. It is recommended that teachers provide children with more time for physical games and activities in their daily schedule instead of keeping children seated for long periods of time in classrooms to learn Pinyin, simple characters, or numeracy, especially in separate preprimary classes-a common type of early childhood education in rural China-and in Grade 1 classes that enroll young children in resource-constrained areas (Rao et al., 2012). Teachers should not emphasize competition or mastery of physical skills during these activities but should attach importance to children's enjoyment and development of interest and self-confidence in the process (Diamond \& Lee, 2011).

In addition, as an important form of learning for young children, play may also be applied in rural preschool programs. Although play-based activities are strongly recommended for kindergartens and preschools in China (State Education Commission, 2001), few such programs in rural areas have included the concept. Studies in the Western context have shown that play facilitates children's development of self-regulation skills (Tominey \& McClelland, 2011). Therefore, free play should be included in the schedule of activities for rural preschool programs. Furthermore, rigorous studies should be conducted to evaluate whether interventions involving play-based activities and/or free play improve children's EC.

This study found that maternal education level was a significant correlate of children's EC and academic achievement. Thus, related interventions for mothers may help enhance children's development of EC. Such interventions may include lectures on the concept of EC and its development and the introduction of strategies to promote EC in children, for instance, positive ways of responding to children, providing positive guidance, arranging particular games or play, and so on (Center on the Developing Child at Harvard University, 2014; Eisenberg et al., 2010).

Although this study contributes to the limited literature on self-regulation and academic achievement in Chinese children, it has several limitations. First, the study was only conducted in one rural county in western China, and the sample size was small. Future studies should recruit more diverse samples of rural children to examine further the development of selfregulation skills and their influence on other child outcomes. Second, the study did not include other important control variables. For instance, children's initial general cognitive abilities, which contribute to academic competencies, were not assessed. Children's working memory and nonverbal intelligence, which have been found to be closely related to EC (Zhou et al., 2012), were also not examined. Thus, future related studies should include such control variables. Third, children's EC at the end of Grade 2 was not examined, which makes it impossible to analyze whether growth in literacy or mathematics achievement during Grade 1 would predict EC in Grade 2. Considering that the prediction of academic achievement from self-regulation skills was not stable during different preschool or school years (Fuhs, Nesbitt, Farran, \& Dong, 2014; Stipek et al., 2010), further studies are required to explore patterns of relationships between these two abilities in Chinese children. Fourth, the study followed children across 2 years, but whether the relationship between EC and academic achievement lasts as children are promoted to higher grades is not clear. Therefore, future studies should pay attention to the longer term association between children's EC and academic achievement. 
In conclusion, we found that EC predicted academic achievement among children in the early primary school years in rural China. Studies in Western contexts have revealed the positive effect of EC on children's school achievement (Cadima et al., 2015; Gestsdottir et al., 2014; Størksen et al., 2015; Wanless et al., 2013), and by extending the sample and by adopting different measures this study obtained similar findings. This means that findings related to the link between EC and academic achievement in Western contexts can be applied to Chinese contexts. Findings suggest that experts should foster children's EC skills, such as behavioral and emotional control and attention persistence and shifting, during children's preschool and early primary school years to promote their school readiness, adjustment, and achievement.

\section{Acknowledgments}

We express our sincere appreciation to the research assistants, teachers, and children who participated in this project. This study was based on research conducted by the first author in partial fulfillment of the requirements of a doctoral degree (2013) under the supervision of the second author and collaborative research work with the research team of the second author.

\section{Funding}

This research was supported by Grant No. 2015EJY002 from the Shanghai Planning Office of Philosophy and Social Science, China, and by the Peak Discipline Construction Project of Education at East China Normal University.

\section{References}

Blair, C., Calkins, S., \& Kopp, L. (2010). Self-regulation as the interface of emotional and cognitive development. In R. H. Hoyle (Ed.), Handbook of personality and self-regulation (pp. 64-90). Chichester, UK: Wiley-Blackwell.

Blair, C., \& Razza, R. P. (2007). Relating effortful control, executive function, and false belief understanding to emerging math and literacy ability in kindergarten. Child Development, 78(2), 647-663. doi:10.1111/cdev.2007.78. issue-2

Blair, C., Ursache, A., Greenberg, M., \& Vernon-Feagans, L. (2015). Multiple aspects of self-regulation uniquely predict mathematics but not letter-word knowledge in the early elementary grades. Developmental Psychology, 51 (4), 459-472. doi:10.1037/a0038813

Cadima, J., Gamelas, A. M., McClelland, M., \& Peixoto, C. (2015). Associations between early family risk, children's behavioral regulation, and academic achievement in Portugal. Early Education \& Development, 26(5-6), 708-728. doi:10.1080/10409289.2015.1005729

Cameron, C. E., McClelland, M. M., Matthews, J. S., \& Morrison, F. J. (2009). A structured observation of behavioral self-regulation and its contribution to kindergarten outcomes. Developmental Psychology, 45(3), 605-619. doi:10.1037/a0015365

Campbell, M. J., \& Swinscow, T. D. V. (2009). Statistics at square one (11th ed.). London, UK: BMJ.

Center on the Developing Child at Harvard University. (2014). Enhancing and practicing executive function skills with children from infancy to adolescence. Retrieved from http://www.developingchild.harvard.edu

Chen, L. J., Yang, D. L., \& Ren, Q. (2015). Report on the state of children in China. Chicago, IL: Chapin Hall at the University of Chicago.

Chen, S. H., Main, A., Zhou, Q., Bunge, S. A., Lau, N., \& Chu, K. (2015). Effortful control and early academic achievement of Chinese American children in immigrant families. Early Childhood Research Quarterly, 30, 45-56. doi:10.1016/j.ecresq.2014.08.004

Chen, X., Wang, L., \& Cao, R. (2011). Shyness-sensitivity and unsociability in rural Chinese children: Relations with social, school, and psychological adjustment. Child Development, 82(5), 1531-1543. doi:10.1111/j.1467-8624.2011.01616.x

Chung, K. K. H., Liu, H., Mcbride, C., Wong, A. M. Y., \& Lo, J. C. M. (2016). How socioeconomic status, executive functioning and verbal interactions contribute to early academic achievement in Chinese children. Educational Psychology, 1-19. doi:10.1080/01443410.2016.1179264

Diamond, A. (2012). Activities and programs that improve children's executive functions. Current Directions in Psychological Science, 21(5), 335-341. doi:10.1177/0963721412453722

Diamond, A., Barnett, W. S., Thomas, J., \& Munro, S. (2007, November 30). Preschool program improves cognitive control. Science, 318, 1387-1388. doi:10.1126/science.1151148

Diamond, A., \& Lee, K. (2011, August 19). Interventions shown to aid executive function development in children 4 to 12 years old. Science, 333, 959-964. doi:10.1126/science.1204529 
Eisenberg, N., Vidmar, M., Spinrad, T. L., Eggum, N. D., Edwards, A., Gaertner, B., \& Kupfer, A. (2010). Mothers' teaching strategies and children's effortful control: A longitudinal study. Developmental Psychology, 46(5), $1294-1308$. doi: $10.1037 / \mathrm{a} 0020236$

Evans, E. M., Schweingruber, H., \& Stevenson, H. W. (2002). Gender differences in interest and knowledge acquisition: The United States, Taiwan, and Japan. Sex Roles, 47(3-4), 153-167. doi:10.1023/A:1021047122532

Fuhs, M. W., Nesbitt, K. T., Farran, D. C., \& Dong, N. (2014). Longitudinal associations between executive functioning and academic skills across content areas. Developmental Psychology, 50(6), 1698-1709. doi:10.1037/a0036633

Gestsdottir, S., Von Suchodoletz, A., Wanless, S. B., Hubert, B., Guimard, P., Birgisdottir, F., ... McClelland, M. (2014). Early behavioral self-regulation, academic achievement, and gender: Longitudinal findings from France, Germany, and Iceland. Applied Developmental Science, 18(2), 90-109. doi:10.1080/10888691.2014.894870

Howse, R. B., Lange, G., Farran, D. C., \& Boyles, C. D. (2003). Motivation and self-regulation as predictors of achievement in economically disadvantaged young children. Journal of Experimental Education, 71(2), $151-174$. doi:10.1080/00220970309602061

Institute of Curriculum and Teaching Materials, \& Research and Development Center for Language Curriculum and Teaching Materials for Primary Schools. (2007). Yu Wen (1B). Beijing, China: People's Education Press.

Institute of Curriculum and Teaching Materials, \& Research and Development Center for Language Curriculum and Teaching Materials for Primary Schools. (2008a). Yu Wen (1A). Beijing, China: People's Education Press.

Institute of Curriculum and Teaching Materials, \& Research and Development Center for Language Curriculum and Teaching Materials for Primary Schools. (2008b). Yu Wen (2A). Beijing, China: People's Education Press.

Institute of Curriculum and Teaching Materials, \& Research and Development Center for Language Curriculum and Teaching Materials for Primary Schools. (2008c). Yu Wen (2B). Beijing, China: People's Education Press.

Kline, R. B. (2011). Principles and practice of structural equation modeling (3rd ed.). New York, NY: Guilford Press.

Lan, X., Cameron, C. E., Miller, K. F., Li, S., Cortina, K., Perry, M., \& Fang, G. (2009). Keeping their attention: Classroom practices associated with behavioral engagement in first grade mathematics classes in China and the United States. Early Childhood Research Quarterly, 24(2), 198-211. doi:10.1016/j.ecresq.2009.03.002

Li-Grining, C. P., Votruba-Drzal, E., Maldonado-Carreno, C., \& Haas, K. (2010). Children's early approaches to learning and academic trajectories through fifth grade. Developmental Psychology, 46(5), 1062-1077. doi:10.1037/ a0020066

Liew, J., Chen, Q., \& Hughes, J. N. (2010). Child effortful control, teacher-student relationships, and achievement in academically at-risk children: Additive and interactive effects. Early Childhood Research Quarterly, 25, 51-64. doi:10.1016/j.ecresq.2009.07.005

Liew, J., McTigue, E. M., Barrois, L., \& Hughes, J. N. (2008). Adaptive and effortful control and academic self-efficacy beliefs on achievement: A longitudinal study of 1st through 3rd graders. Early Childhood Research Quarterly, 23(4), 515-526. doi:10.1016/j.ecresq.2008.07.003

Liu, J. B., \& Elicker, J. (2005). Teacher-child interaction in Chinese kindergartens: An observational analysis. International Journal of Early Years Education, 13(2), 129-143. doi:10.1080/09669760500171139

Luo, R., Tamis-LeMonda, C. S., \& Song, L. (2013). Chinese parents' goals and practices in early childhood. Early Childhood Research Quarterly, 28(4), 843-857. doi:10.1016/j.ecresq.2013.08.001

Ma. (2015). China releases white paper on left-behind children. Retrieved from http://english.cri.cn/12394/2015/06/19/ 4082s883760.htm

McClelland, M. M., Acock, A. C., \& Morrison, F. J. (2006). The impact of kindergarten learning-related skills on academic trajectories at the end of elementary school. Early Childhood Research Quarterly, 21(4), 471-490. doi:10.1016/j.ecresq.2006.09.003

McClelland, M. M., Acock, A. C., Piccinin, A., Rhea, S. A., \& Stallings, M. C. (2013). Relations between preschool attention span-persistence and age 25 educational outcomes. Early Childhood Research Quarterly, 28(2), 314-324. doi:10.1016/j.ecresq.2012.07.008

Ministry of Education. (2002a). Guidelines on language curriculum for full day primary schools in the nine year compulsory education system (trial version). Beijing, China: People's Education Press.

Ministry of Education. (2002b). Guidelines on mathematics curriculum for full day primary schools in the nine year compulsory education system (trial version). Beijing, China: People's Education Press.

National Bureau of Statistics of the People's Republic of China. (2009, September 10). Series report four: Urban and rural residents gradually move towards a well-off from poverty. Retrieved from http://www.stats.gov.cn/ztjc/ztfx/ qzxzgcl60zn/200909/t20090910_68636.html

Organisation for Economic Co-operation and Development. (2014, February). PISA 2012 results: What students know and can do-Student performance in mathematics, reading and science (Vol. 1, Rev. ed.). Pisa, Italy: OECD Publishing.

Pang, Y., \& Richey, D. (2007). Preschool education in China and the United States: A personal perspective. Early Child Development and Care, 177(1), 1-13. doi:10.1080/14797580500252712

Rao, N., Ng, S. S. N., \& Pearson, E. (2010). Preschool pedagogy: A fusion of traditional Chinese beliefs and contemporary notions of appropriate practice. In C. K. K. Chan \& N. Rao (Eds.), Revisiting the Chinese learner: 
Changing contexts, changing education (pp. 255-279). Hong Kong: Comparative Education Research Centre, The University of Hong Kong.

Rao, N., Sun, J., Wong, J. M. S., Weekes, B., Ip, P., Shaeffer, S., ... Lee, D. (2014). Early childhood development and cognitive development in developing countries: A rigorous literature review. London, UK: Department for International Development.

Rao, N., Sun, J., \& Zhang, L. (2014). Learning to learn in early childhood: Home and preschool influences in Chinese societies. In C. Stringher \& R. Deakin Crick (Eds.), Learning to learn for all: Theory, practice and international research: A multidisciplinary and lifelong perspective (pp. 127-144). Abingdon, UK: Taylor \& Francis.

Rao, N., Sun, J., Zhou, J., \& Zhang, L. (2012). Early achievement in rural China: The role of preschool experience. Early Childhood Research Quarterly, 27(1), 66-76. doi:10.1016/j.ecresq.2011.07.001

Ready, D. D., LoGerfo, L. F., Burkam, D. T., \& Lee, V. E. (2005). Explaining girls' advantage in kindergarten literacy learning: Do classroom behaviors make a difference? The Elementary School Journal, 106(1), 21-38. doi:10.1086/496905

Rothbart, M. K., \& Bates, J. E. (2006). Temperament. In W. Damon \& N. Eisenberg (Eds.), Handbook of child psychology: Vol. 3. Emotional and personality development (6th ed., pp. 99-166). New York, NY: Wiley.

Schmitt, S. A., McClelland, M. M., Tominey, S. L., \& Acock, A. C. (2015). Strengthening school readiness for Head Start children: Evaluation of a self-regulation intervention. Early Childhood Research Quarterly, 30, 20-31. doi:10.1016/j.ecresq.2014.08.001

Sektnan, M., McClelland, M. M., Acock, A. C., \& Morrison, F. J. (2010). Relations between early family risk, children's behavioral regulation, and academic achievement. Early Childhood Research Quarterly, 25(4), 464-479. doi:10.1016/ j.ecresq.2010.02.005

Son, S.-H., Lee, K., \& Sung, M. (2013). Links between preschoolers' behavioral regulation and school readiness skills: The role of child gender. Early Education \& Development, 24(4), 468-490. doi:10.1080/10409289.2012.675548

SPSS Inc. (2008). SPSS missing values 17.0. Chicago, IL: Author.

State Education Commission. (2001). Guideline framework of kindergarten education (on a trial basis). Beijing, China: State Education Commission of the People's Republic of China.

Stipek, D., Newton, S., \& Chudgar, A. (2010). Learning-related behaviors and literacy achievement in elementary school-aged children. Early Childhood Research Quarterly, 25, 385-395. doi:10.1016/j.ecresq.2009.12.001

Størksen, I., Ellingsen, I. T., Wanless, S. B., \& McClelland, M. M. (2015). The influence of parental socioeconomic background and gender on self-regulation among 5-year-old children in Norway. Early Education \& Development, 26(5-6), 663-684. doi:10.1080/10409289.2014.932238

Swanson, J., Valiente, C., Lemery-Chalfant, K., Bradley, R. H., \& Eggum-Wilkens, N. D. (2014). Longitudinal relations among parents' reactions to children's negative emotions, effortful control, and math achievement in early elementary school. Child Development, 85(5), 1932-1947.

The Government of ABC County. (2009). Background information of ABC County. ABC County: Author.

Tobin, J. J., Hsueh, Y., \& Karasawa, M. (2009). Preschool in three cultures revisited: China, Japan, and the United States. Chicago, IL: University of Chicago Press.

Tominey, S. L., \& McClelland, M. M. (2011). Red light, purple light: Findings from a randomized trial using circle time games to improve behavioral self-regulation in preschool. Early Education \& Development, 22(3), 489-519. doi:10.1080/10409289.2011.574258

Valiente, C., Eisenberg, N., Haugen, R., Spinrad, T. L., Hofer, C., Liew, J., \& Kupfer, A. (2011). Children's effortful control and academic achievement: Mediation through social functioning. Early Education \& Development, 22(3), 411-433. doi:10.1080/10409289.2010.505259

Valiente, C., Lemery-Chalfant, K., \& Castro, K. S. (2007). Children's effortful control and academic competence: Mediation through school liking. Merrill-Palmer Quarterly, 53(1), 1-25. doi:10.1353/mpq.2007.0006

Valiente, C., Lemery-Chalfant, K., Swanson, J., \& Reiser, M. (2008). Prediction of children's academic competence from their effortful control, relationships, and classroom participation. Journal of Educational Psychology, 100(1), 67-77. doi:10.1037/0022-0663.100.1.67

Wanless, S. B., McClelland, M. M., Lan, X., Son, S.-H., Cameron, C. E., Morrison, F. J., ... Sung, M. (2013). Gender differences in behavioral regulation in four societies: The United States, Taiwan, South Korea, and China. Early Childhood Research Quarterly, 28(3), 621-633. doi:10.1016/j.ecresq.2013.04.002

Welsh, J. A., Nix, R. L., Blair, C., Bierman, K. L., \& Nelson, K. E. (2010). The development of cognitive skills and gains in academic school readiness for children from low-income families. Journal of Educational Psychology, 102(1), 43-53. doi: $10.1037 / \mathrm{a} 0016738$

Wu, J. (2016). Fabricating an educational miracle: Compulsory schooling meets ethnic rural development in Southwest China. Albany: State University of New York Press.

Zhang, L. (2008). The cognitive school readiness development of preschool left-behind children in rural China (Unpublished master's thesis). East China Normal University, Shanghai, China.

Zhou, Q., Chen, S. H., \& Main, A. (2012). Commonalities and differences in the research on children's effortful control and executive function: A call for an integrated model of self-regulation. Child Development Perspectives, 6(3), 112121. doi:10.1111/j.1750-8606.2011.00176.x 
Zhou, Q., Main, A., \& Wang, Y. (2010). The relations of temperamental effortful control and anger/frustration to Chinese children's academic achievement and social adjustment: A longitudinal study. Journal of Educational Psychology, 102(1), 180-196. doi:10.1037/a0015908

\section{Appendix}

Academic Achievement Tests

Test of Literacy Achievement for Grade 1 Children (Excerpted)

$\mathrm{NO}$ :

Code of School: Code of the child:

Early Education:1.kindergarten 2.pre-primary 3.Grade 1 with sitting-in children 4.No

\section{I Can Read}

2. Put four tones on the following vowels or syllables.

ei ei ei ei hua hua hua hua

4. Choose the right pronunciation with a tick.

Listening to music (lè yuè) is a happy (lè yuè) thing.

\section{I Can Write}

2. Choose the right radicals.

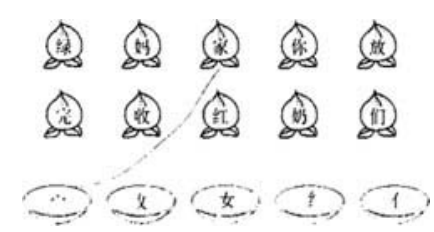

3. Write down the Chinese characters according to the following Pinyin.

chūn jié lǜ căo péng yǒu xiăng niàn
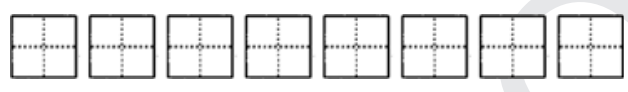

6. Complete the sentences.

I help everyone

7. Read the rhyme and answer questions.

Spring comes and the flowers laugh,

Summer comes and the cicadas make sound,

Autumn comes and the maple leaves turn red,

Winter comes and it snows.

1) In spring the flowers

8. Write about the picture.

Look at the following picture. Please first give names to the three kids and then write something about what they were doing.

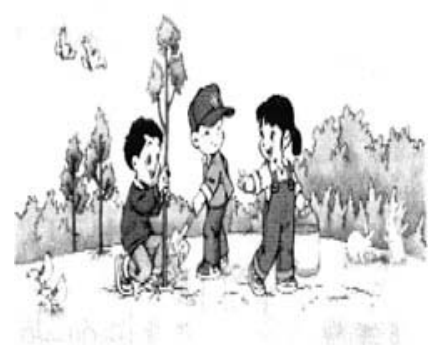


Test of Mathematics Achievement for Grade 1 Children (Excerpted)

NO:

Code of School: Code of the child:

Early Education:1.kindergarten 2.pre-primary 3.Grade 1 with sitting-in children 4.No I. I Can Count

1.

7. Fill out the numbers according to rules.
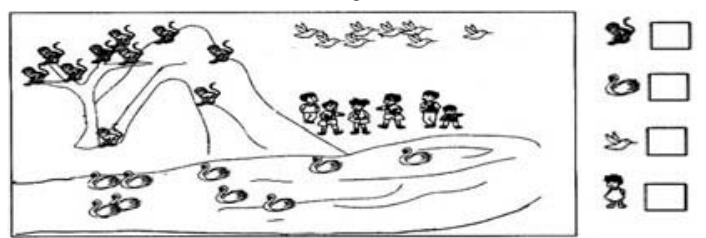

II. I Can Compare

1. Put a $\sqrt{ }$ in the bracket if the symbols in the related line are more and a $\circ$ if less.

(1) 0000000 ( ) (2) \&\&\&\&\&\&\&( )

$$
\Delta \Delta \Delta \Delta \Delta \text { ( ) ○○○○( ( ) }
$$

III. I Can Calculate

1.

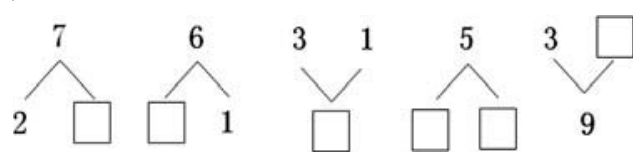

\section{Simple calculation}

$2+3=8+6=$

4.
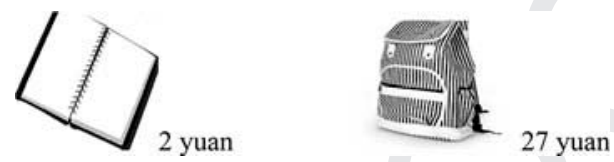

1) Xiao Ming bought one bag with 100 yuan and how many changes would he get?

2) How much is one bag and a booklet?

Test of Literacy Achievement for Grade 2 Children (Excerpted)

Code of School: Code of the child:

Early Education:1.kindergarten 2.pre-primary 3. Grade 1 with sitting-in children 4.No

I. Write down the Chinese characters according to the following Pinyin. (8 points)

jiāo ào qīng cuì xīn xiān zhěng qí

() () () ()

IV. Make comparison of each two characters in each group and join words.

(8 points)

Wei ( ) Pu ( ) Du ( ) Bo ( )

$\mathrm{V}$. Add an radical to each word and then join words. (12 points)

qi- ( ) ( ) qing- ( ) ( ) ji- ( ) ( )

VII. Make up sentences with the given words and put appropriate punctuation marks. $\square 8$ points $\square$

1.courtyard we there is a home in the north of jujube tree

VII. Complete the sentences according to the examples.(6 points)

1. For example : The tails of the swallows are just like scissors.

The stars all over the sky are like scattering in the plate made of jade.

IX. Read the essay and answer questions. $(1+2+4+3+3=13$ points)

Guilin 
It is always said that Guilin is the most famous tourist attraction in China. Once I was lucky to have a tour there. It is really like a brilliant pearl sparkling in the sky. Green hills, beautiful stones, wonderful water and queer caves attract millions of tourists inside and outside of China.

Lijiang Scenic area is the world's largest and most beautiful scenery of karst landscape recreation area. We can enjoy different views of it under different weather conditions. On sunny days, we can have a look at the reflection of green mountains on the waters.

1. In the dictionary, "Jia" has several meanings:(1)the first(2)personnel body armour for the army in the ancient times.(3) shells of animals. In the sentence "Guilin Shan Shui Jia Tian Xia", the meaning of "Jia" is ().

$\mathrm{X}$. Write about the picture. (14 points)

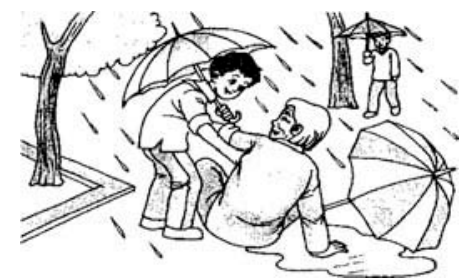

Look at the following picture. Think about who is suffered from what kind of problems. What do students do when they saw what had happened? What did they think? What did they say? What did they do?

Test of Mathematics Achievement for Grade 2 Children (Excerpted)

Code of School: Code of the child:

Early Education:1.kindergarten 2.pre-primary 3. Grade 1 with sitting-in children 4.No

I. Fill in the brackets.(30 points)

1. Fill in the brackets with appropriate measuring units.

(1)A goat weigh 4,999 ( ), approximately 5 ( );

2. Fill in the brackets with appropriate figures.

(1) 3 meters 60centimeters $=($ ) centimeters; (2)500 centimeters $=($ ) meters;

6. Fill in the owith"> ““<“或” = " $\times$ ”“ $\div$ ”“+”“-”

$6889 \circ 68985 \circ 7=3539 \circ 6 \times 8 \quad 21 \circ 3=7 \quad 18 \div 2 \circ 2 \times 3$

II. Make a choice. ( 8 points)

1. Make comparison between 1 kilogram of iron and 1 kilogram of cotton. Which weighs more? ()

(1)iron (2) cotton (3)They are of the same weight. (4) Not sure

III. Calculation.(24 points)

Simple calculation. ( 12 points )

$72 \div 8=56-29=170-90=430+350=2 \times 9 \div 3=$

IV. Draw appropriate pictures. (8 points)

1. Draw an acute angle. (2 points)

V. Problem solving (30 points).

1. Xiao Hong and Xiao Ming planted trees together. Xiao Hong planted 3 rows of pulm trees with 5 in each row. Xiao

Ming planted 7 rows of Peach trees with 3 in each row. How many trees did they plant altogether? (4 points) 